\title{
Increase in hospital admissions for childhood asthma: trends in referral, severity, and readmissions from 1970 to 1985 in a health region of the United Kingdom
}

\author{
H R ANDERSON \\ From the Department of Clinical Epidemiology and Social Medicine, St George's Hospital Medical School, \\ London
}

ABSTRACT Admissions to hospital for childhood asthma have continued to increase, but the reasons are unknown. Because the incidence of acute asthmatic attacks in the community greatly exceeds the admission rate, this increase could be a result of changes in medical practice shifting the balance of care towards the hospital without there being any underlying change in morbidity. In the South West Thames Region (population 2.9 million) over the eight years 1978-85 the number of hospital admissions among those aged $0-4$ and 5-14 rose by $186 \%$ and $56 \%$. A random sample of case notes from all hospitals in the region was examined for evidence of changes in mode of referral, severity on admission (duration of episode, vital signs on admission), and readmission ratio. The findings indicate that there has been no reduction in severity on admission or increase in readmission rate since 1978. The findings for the 5-14 age group contrast with those from an earlier study (1970-8) in the same region, in which a substantial increase in self referral was observed together with an increase in readmissions and a reduction in the duration of the attack; pulse and respiration rates on admission have, however, remained unchanged over the 16 year period. Overall, these findings indicate that the increase in admissions cannot be satisfactorily explained by changes in medical practice alone and may be due to an increase in the number of asthmatic children experiencing severe attacks. This points to a change in the epidemiology of childhood asthma.

\section{Introduction}

From 1958 to 1985 hospital admissions for childhood asthma in England and Wales increased by $1300 \%$ in the $0-4$ age group and by $600 \%$ in the 5-14 age group (fig 1). The mean annual rate of increase since 1980 has been $20 \%$ for the younger and $12 \%$ for the older age group.' A similar trend has been reported from some other developed countries. ${ }^{2}$ The increase cannot be explained by diagnostic transfer from other lower respiratory conditions, such as acute bronchitis, or by changes in the ICD classification. ${ }^{34}$ It is important to find out whether this increase is due to an increase in

Address for reprint requests: Professor H R Anderson, Department of Clinical Epidemiology and Social Medicine, St George's Hospital Medical School, London SW17 ORE.

Accepted 4 May 1989 morbidity or to changes in the recognition and management of childhood asthma, or to both.

A previous comparison of hospital records of children aged 5-14 admitted with asthma during 1970-8 in one region in England (South West Thames) found evidence of a substantial shift towards self referral and an increase in readmissions; there was no apparent decline in clinical severity on admission as indicated by vital signs but the duration of symptoms before admission had decreased.5 Since then the upward trend in admissions has continued both nationally and regionally. This paper reports a further survey in 1985 of admissions for childhood asthma within the same region. The aim was to look for further evidence that might help to explain the continuing increase in admissions. For the 5-14 age group data are presented for the whole period 1970-85. For the 0-4 age group data are presented for 1978-85. Data on management before and after admission are the subject of a separate paper. 


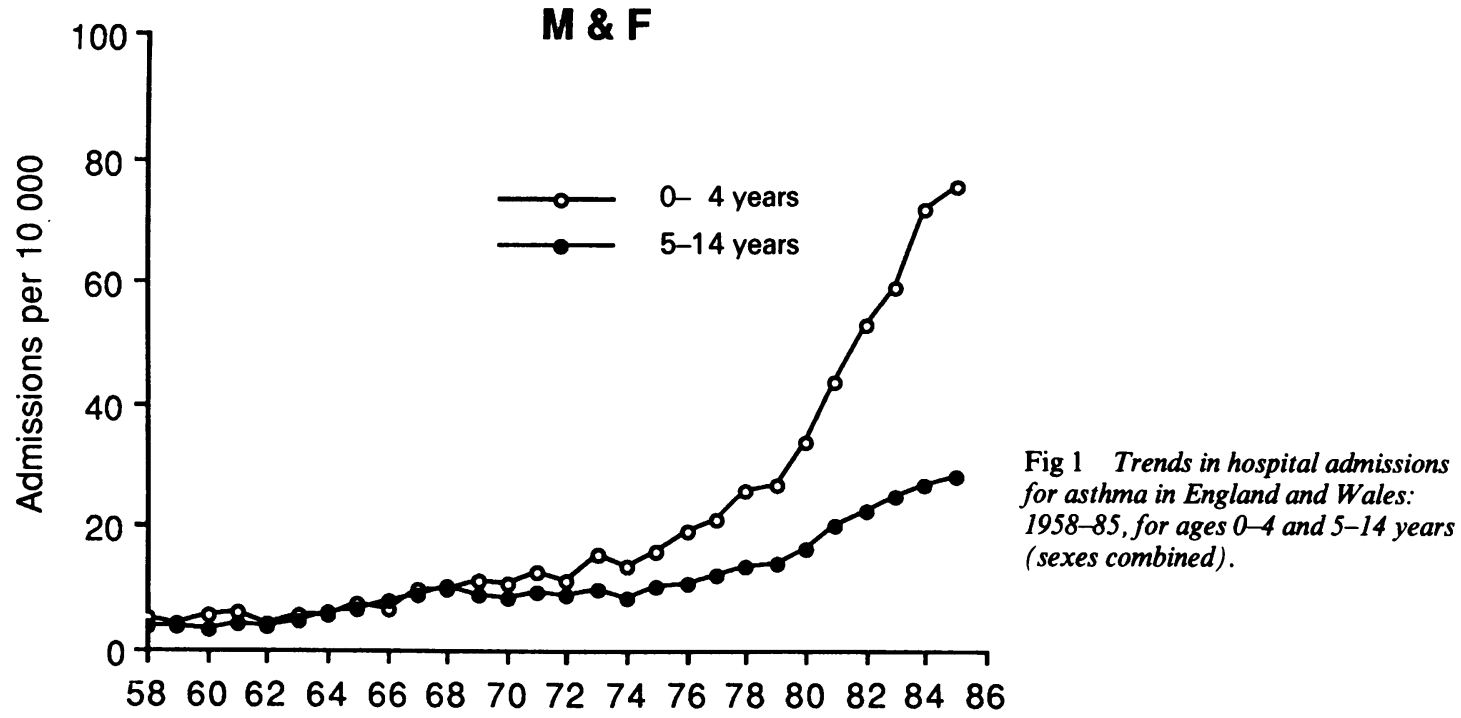

Year

\section{Methods}

The methods were those used in the previous study in all important respects. ${ }^{5}$ One hospital included in the previous study was excluded because it now lay outside the regional boundaries as a result of the reorganisation in 1981. A list of all children under 15 years admitted with a first diagnosis of asthma (ICD 493) was obtained from Hospital Activity Analysis for the years 1978 and 1985 . We approached the responsible consultants for permission to examine the case notes, and obtained approval from the ethical committees of all 13 health districts within the South West Thames Region.

The target sample was 600 . This comprised 200 each for the 0-4 year age group in 1978 and 1985 and the 5-14 year age group in 1985 (1970 and 1978 data from the latter group were available from the previous study). All individuals with an immediate admission for asthma were numbered by hospital and by each year and age group. Where an individual had been admitted more than once, one admission was selected randomly. The sampling fractions were $56 \%$ for the $19780-4$ year group, $21 \%$ for the $19850-4$ year group, and $26 \%$ for the 1985 5-14 year group. Using these sampling fractions, we calculated target samples for each group for each of the 16 hospitals. Within each hospital the serial number of each patient was permutated and the notes were examined in that order. This enabled the target sample to be reached despite some missing notes. Data extracted from the notes included mode of referral, duration of episode, vital signs (pulse and respiratory rate) on admission, treatment in the 24 hours before and after admission, and investigations. From the Hospital Activity Analysis listing readmissions within the calendar year of the index admission were recorded. Data on trends in admissions for other lower respiratory conditions were obtained from the same source. Population estimates and mortality data were obtained from published sources. $^{6}$

For comparison of trends in categorical data the $\chi^{2}$ test for trend was used and for continuous variables Student's $t$ test.

\section{Results}

The trends in the number of children admitted to the region's hospitals for asthma during the study period are shown in figure 2 . In this section comparisons refer mainly to trends for 1978-85, but the earlier data from 1970 for the 5-14 age group will also be presented and discussed where relevant. Admissions among the 0-4 age group showed an increase of $186 \%$ from 1978 to 1985; the calendar year readmission ratio remained largely unchanged at around $1 \cdot 5$. There was no trend in admissions for bronchitis (ICD 466 and 490) in this age group. From 1978 to 1985 admissions among the 5-14 age group increased by $56 \%$ whereas admissions for bronchitis decreased by $20 \%$ (to 66 ). The readmission ratio fell slightly from 1.47 to 1.32 , which was the ratio in the early 1970s. From 1978 to 1985 the population aged $0-4$ increased by $10 \%$ whereas $5-14$ year olds decreased by $19 \%$; thus the numbers shown 

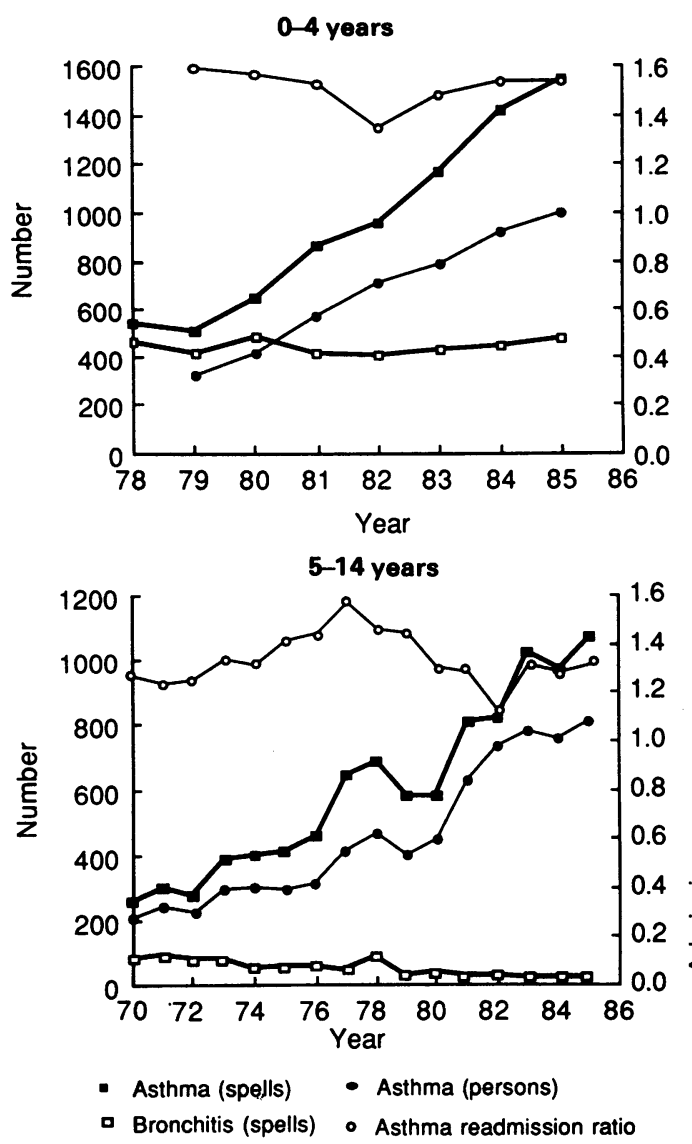

Fig 2 Trends in hospital admissions for asthma (spells and persons) and bronchitis (spells only) and readmission ratios in the South West Thames Region: 1978-85 for ages 0-4 years and 1970-85 for 5-14 years. slightly overestimate the trend for the $0-4$ age group and slightly underestimate the trend for the 5-14 age $\stackrel{D}{\stackrel{D}{9}}$ group. There were four deaths in 1978 and three $\bar{C}$ deaths in 1985, and the annual average mortality over this period was $2 \cdot 8$ deaths a year.

Seven hundred and eighty case notes were searched $\stackrel{\nabla}{\circ}$ to obtain the final sample of 599 (77\% response). The proportion not found did not differ between age groups or year. Table 1 shows the trends in length of $\bigcirc$ stay, readmissions, mode of referral, and character- $\vec{\omega}$ istics of the referring doctor. The $0-4$ age group showed little or no change in length of stay or in $\vec{x}$ readmission ratio. There was no significant change in the proportion referred by their general practitioner, though the tendency was for the proportion of general os practitioner referrals to fall. The proportion of general $\vec{A}$ practitioner referrals by a doctor from the patient's 윽 registered practice remained high at over $90 \%$. There was no significant change in the time of day the child was admitted.

From 1978 to 1985 the 5-14 age group showed no significant trends in mode of referral, though there was $\vec{\theta}$ a tendency for self referral to increase, and for contact $\&$ with the general practitioner earlier in the episode preceding self referral to decrease. There was no significant change in time of admission (data not shown). The readmission ratio fell from 1.42 to $1 \cdot 26$. When the data from 1970 were included in the analysis $ᄋ$ of the data on the 5-14 age group a significant trend towards self referral $(22 \%$ to $52 \%)$ was found, but this $\overline{\bar{O}}$ had largely occurred before 1978 . The readmission ratio in 1970 was close to that in 1985 but the ratio was highest in the mid period. Around $80 \%$ of this age group had been referred by a doctor of the practice with which the patient was registered and no trend over time was seen.

Trends in the duration of the episode and in pulse

Table 1 Trends in length of hospital stay, readmission ratio, mode of referral, and characteristics of referring doctor: $0-4$ years (1978-85) and 5-14 years (1970-85)

\begin{tabular}{|c|c|c|c|c|c|}
\hline & \multicolumn{3}{|c|}{$5-14$ years } & \multicolumn{2}{|c|}{$0-4$ years } \\
\hline & 1970 & 1978 & 1985 & 1978 & 1985 \\
\hline $\begin{array}{l}\text { No of admissions (spells) } \\
\text { No of admissions (persons) } \\
\text { No in sample (persons) }\end{array}$ & $\begin{array}{l}256 \\
202 \\
178\end{array}$ & $\begin{array}{l}684 \\
465 \\
210\end{array}$ & $\begin{array}{r}1070 \\
808 \\
202\end{array}$ & $\begin{array}{l}540 \\
358 \\
190\end{array}$ & $\begin{array}{r}1542 \\
1002 \\
207\end{array}$ \\
\hline $\begin{array}{l}\text { Mean age (years) } \\
\text { Median length of stay (days) } \\
\text { Mean length of stay (days) } \\
\text { Admissions per person in calendar year of admission }\end{array}$ & $\begin{array}{l}8 \cdot 6 \\
5 \\
6 \cdot 2 \\
1 \cdot 22\end{array}$ & $\begin{array}{l}8 \cdot 9 \\
3 \\
3 \cdot 4 \\
1 \cdot 42\end{array}$ & $\begin{array}{l}8 \cdot 2 \\
2 \\
2 \cdot 6 \\
1 \cdot 26\end{array}$ & $\begin{array}{l}2 \cdot 5 \\
2 \\
2 \cdot 7 \\
1 \cdot 5\end{array}$ & $\begin{array}{l}2 \cdot 3 \\
2 \\
2 \cdot 6 \\
1 \cdot 5\end{array}$ \\
\hline $\begin{array}{l}\text { Mode of referral (\%) } \\
\text { GP* } \\
\text { Self } \\
\text { (saw GP earlier in episode) } \\
\text { No information and other }\end{array}$ & $\begin{array}{l}70 \\
22 \\
(8) \\
8\end{array}$ & $\begin{array}{r}48 \\
44 \\
(10) \\
8\end{array}$ & $\begin{array}{r}45 \\
52 \\
(8) \\
3\end{array}$ & $\begin{array}{c}66 \\
34 \\
(7) \\
0\end{array}$ & $\begin{array}{c}61 \\
36 \\
(4) \\
3\end{array}$ \\
\hline $\begin{array}{l}\text { Characteristics of referring doctor } \\
\text { Number referred by GP } \\
\text { Number of legible letters } \\
\text { Doctor from patient's registered practice (\%) } \\
\text { Doctor was principal in patient's practice (\%) } \\
\text { Locum or relief service(\%) }\end{array}$ & $\begin{array}{r}125 \\
119 \\
85 \\
57 \\
11\end{array}$ & $\begin{array}{r}101 \\
92 \\
80 \\
48 \\
7\end{array}$ & $\begin{array}{r}91 \\
71 \\
92 \\
77 \\
7\end{array}$ & $\begin{array}{r}125 \\
102 \\
95 \\
95 \\
4\end{array}$ & $\begin{array}{r}126 \\
104 \\
92 \\
86 \\
7\end{array}$ \\
\hline
\end{tabular}


Table 2 Trends in duration of episode before admission and in pulse and respiration rates on admission: 0-4 years (1978-85) and 5-14 years (1970-85)

\begin{tabular}{|c|c|c|c|c|c|}
\hline & \multicolumn{3}{|c|}{ 5-14 years } & \multicolumn{2}{|l|}{$0-4$ years } \\
\hline & 1970 & 1978 & 1985 & 1978 & 1985 \\
\hline $\begin{array}{l}\text { No of persons admitted } \\
\text { No in sample }\end{array}$ & $\begin{array}{l}256 \\
178\end{array}$ & $\begin{array}{l}684 \\
210\end{array}$ & $\begin{array}{r}1070 \\
202\end{array}$ & $\begin{array}{l}540 \\
190\end{array}$ & $\begin{array}{r}1542 \\
207\end{array}$ \\
\hline $\begin{array}{l}\text { Duration of episode before admission (\%) } \\
0-17 \text { hours } \\
18-35 \text { hours } \\
36 \text { hours }-7 \text { days } \\
\geqslant 8 \text { days } \\
\text { Pulse rate }(/ \mathrm{min} \text { ) on admission } \\
\text { Mean (SD) } \\
\text { Median } \\
\%>130 / \mathrm{min} \\
\%>140 / \mathrm{min} \\
\text { Respiratory rate (/min) on admission } \\
\text { Mean (SD) }\end{array}$ & $\begin{array}{c}(\mathrm{n}=168 \\
28 \\
32 \\
27 \\
14 \\
(\mathrm{n}=150 \\
119(19) \\
120 \\
22 \\
6 \\
(\mathrm{n}=100 \\
32(8)\end{array}$ & $\begin{array}{l}201 \\
42 \\
26 \\
24 \\
7 \\
202 \\
118(20) \\
120 \\
23 \\
9 \\
149 \\
34(10)\end{array}$ & $\begin{array}{l}189 \\
40 \\
28 \\
26 \\
6 \\
189 \\
118(19) \\
120 \\
20 \\
11 \\
176 \\
35(11)\end{array}$ & $\begin{array}{l}177 \\
64 \\
20 \\
13 \\
2 \\
176 \\
132(20) \\
130 \\
49 \\
23 \\
167 \\
47(13)\end{array}$ & $\begin{array}{l}193) \\
52 \\
22 \\
25 \\
2 \\
189) \\
130(21) \\
130 \\
43 \\
23 \\
188) \\
44(11)\end{array}$ \\
\hline
\end{tabular}

Duration of symptoms: 5-14 y 1970-85 $\chi^{2}$ trend $10.3, p<0.001 ; 1978-85 \chi^{2}$ trend NS.

$$
0-4 \text { y } 1978-85 \chi^{2} \text { trend } 6.77, p<0.01 \text {. }
$$

and respiration rates are shown in table 2 . In the $0-4$ age group there was evidence for a small but significant lengthening of the duration of symptoms before admission but there was no change in pulse rate on admission and the fall of $3 / \mathrm{min}$ in mean respiration rate was not significant. From 1978 to 1985 the 5-14 age group showed no significant shortening in the duration of their symptoms but analysis of the data for 1970-85 showed a significant shortening. There was no evidence of a trend in pulse or respiration rates.

For both age groups similar results were obtained when pulse and respiration rates derived from the routine charts were used instead of the values recorded in the notes. Recovery of pulse rate was assessed from the routine chart at 24 hours and showed no change over time. There was no trend in the proportions reported to have an accompanying upper respiratory tract infection or in body temperature on admission. No patient died.

Comparison of self and general practitioner referrals in 1985 showed important differences (table $3)$. In the 0-4 age group self referred patients were older, had a longer stay in hospital, a higher readmission ratio, and a greater tendency to be admitted between midnight and 11 am. In the 5-14 age group, self referred patients were likely to be older and to have a higher readmission ratio and a longer duration of symptoms. Self referred patients in both age groups had lower pulse and respiration rates but the differences were not significant.

Table 3 Comparison of self and general practitioner referrals in 1985

\begin{tabular}{|c|c|c|c|c|}
\hline & \multicolumn{2}{|l|}{$5-14 y$} & \multicolumn{2}{|l|}{$0-4 y$} \\
\hline & Self & $G P$ & Self & $G P$ \\
\hline No in sample & 105 & 91 & 75 & 126 \\
\hline $\begin{array}{l}\text { Mean (SD) age (years) } \\
\text { Median length of stay (days) } \\
\text { Mean (SD) length of stay (days) } \\
\text { Admissions per person in calendar year of admission } \\
\text { Duration of episode before admission (\%) } \\
0-17 \text { hours } \\
18-35 \text { hours } \\
36 \text { hours- } 7 \text { days } \\
\geqslant 8 \text { days } \\
\text { Pulse rate (/min) on admission } \\
\text { Mean (SD) } \\
\text { Median } \\
\text { Respiratory rate (/min) on admission } \\
\text { Mean (SD) } \\
\text { Median }\end{array}$ & $\begin{aligned} & 8 \cdot 4(2 \cdot 8) \\
& 2 \\
& 2 \cdot 5(1 \cdot 7) \\
& 1 \cdot 4 \\
& n= \\
& 98 \\
& 32 \\
& 28 \\
& 33 \\
& 7 \\
& n=95 \\
& 116(19) \\
& 120 \\
& n=83 \\
& 34(9) \\
& 32\end{aligned}$ & $\begin{array}{l}7 \cdot 8(2 \cdot 6) \\
2 \\
2 \cdot 6(2 \cdot 1) \\
1 \cdot 1 \\
85 \\
51 \\
28 \\
16 \\
7 \\
91 \\
122(20) \\
120 \\
87 \\
37(12) \\
35\end{array}$ & $\begin{array}{l}2 \cdot 6(1 \cdot 3) \\
3 \\
3 \cdot 1(2 \cdot 1) \\
1 \cdot 7 \\
68 \\
47 \\
22 \\
31 \\
0 \\
66 \\
126(20) \\
120 \\
64 \\
42(12) \\
40\end{array}$ & $\begin{array}{l}2 \cdot 2(1 \cdot 2) \\
2 \\
2 \cdot 3(1 \cdot 8) \\
1 \cdot 2 \\
121) \\
55 \\
24 \\
21 \\
0 \\
119) \\
132(23) \\
130 \\
121) \\
45(11) \\
44\end{array}$ \\
\hline
\end{tabular}

$0-4$ years: mean length of stay, GP $v$ self $t=2.79, p<0.01$.

$5-14$ years: duration of episode, GP $v$ self $\chi^{2}$ trend 9.5 , df $1, \mathrm{p}<0.005$. 


\section{Discussion}

Analyses of routine admission statistics and of hospital records alone cannot answer the question of whether the prevalence or severity of asthma is increasing. They may, however, provide an indication of the direction in which the answer may lie. The conceptual basis for thinking about the epidemiological value of hospital statistics is straightforward.' The first step is to look for factors within the information system itself for evidence of artefactual trends due to diagnostic transfer and coding changes. Neither of these factors appears relevant to the increase in admissions for childhood asthma in the South West Thames Region or nationally. ${ }^{34}$ The second step, which I am mainly concerned with here, is to look for evidence of changes in medical practice that might indicate a shift in the balance of care between the community and hospitals. This is an important possibility in view of the large difference between the incidence of acute, severe attacks in the community and the rate of admission. ${ }^{8}$ We know virtually nothing about the range of severity of acute asthma in the community, nor do we know the nature of the relation between severity and the decision to seek admission. The premise adopted in this discussion is that the likelihood of admission increases with clinical severity. If this is so, a shift in the balance of care towards the hospital would be accompanied by evidence of a lower average severity on admission-in other words, a lowering of the "threshold" of severity. In the present study severity was assessed by the only available method-that is, by recording the duration of symptoms before admission and pulse and respiratory rates on admission. In acute adult asthma the pulse rate has been found to correlate with the degree of functional disability and disturbance of blood gases. ${ }^{910} \mathrm{~A}$ study of acute asthma in children did not find an association between the degree of disturbance of blood gases and any of the indicators used in the present study ${ }^{11}$ and, although this may have resulted from the small number (21) or from atypical cases, the validity of the severity indicators we have used must remain an open question. Until more systematic recording of clinical severity using validated measures becomes routine, assessing severity from records will remain unsatisfactory.

There is some evidence that changes in medical care have contributed to the increase in admissions, at least in the 1970s. Our earlier study found that self referral had increased substantially from 1970 to 1978, which suggested that factors relating to medical care were changing. The study by Storr et al ${ }^{12}$ found that the high level of self referral in Brighton $(70 \%)$ was associated with a desire by parents for open access to hospital care and a particular form of treatment (nebuliser treatment) that was introduced in the mid to $\Rightarrow$ late 1970s. We found, however, that from 1978 to $1985 \stackrel{\text { क }}{+}$ there was no significant shift in mode of referralo despite the large overall increase in admissions. In 흠 more recent years the pressure towards admission $\frac{\bar{\sigma}}{-}$ appears to have affected general practitioner referral $\stackrel{\Phi}{\varrho}$ and self referral similarly.

The findings indicate that an increase in morbidity $\vec{A}$ must also be considered. For the period 1978-85. among the $0-4$ age group there was no lowering of $\vec{\omega}$ pulse and respiration rates on admission and there was $\stackrel{?}{?}$ an increase in duration of the episodes leading to $\vec{x}$ admission. Among the 5-14 age group over the same period neither of these indicators changed, though in the earlier period (1970-78) there had been a shorten- $\dot{\circ}$ ing in the duration of symptoms. Taken as a whole, the $\vec{f}$

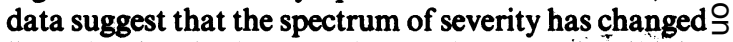
little despite the increase in numbers admitted. The stable readmission ratio in $0-4$ year olds and the falling ratio in 5-14 year olds suggest that more asthmatico children are having severe attacks leading to hospital $\stackrel{\oplus}{+}$ admission. This is consistent with there being more $\overrightarrow{0}$ children with asthma (a higher prevalence) or with an increase in the proportion of asthmatic children having severe attacks. An analysis of prevalence surveys carried out in the United Kingdom over the last 25 years found little or no evidence that the prevalence of children with a label of asthma or $\frac{\varnothing}{\perp}$ symptoms of a wheezing illnes has increased. ${ }^{8}$ Thus an increase in the frequency or severity of episodes in $\overrightarrow{\overrightarrow{\vec{B}}}$ asthmatic children is more likely.

On balance therefore our evidence indicates that the increase in admissions is due to an increase in the frequency of severe asthma rather than to a shift in the balance of care, though the latter explanation cannot $\frac{\text { o }}{2}$ be entirely excluded. If we take readmission ratios and $x$ available data on prevalence into account, the increase $\frac{3}{3}$ in frequency of severe asthma is more likely to be due to an increase in the proportion of asthmatic children $\mathrm{O}$ who have severe attacks than to an increase in the prevalence of asthmatic children. This requires confir-? mation by epidemiological studies.

I thank Mrs Connie Norman, who was responsible for ${ }_{\mathscr{O}}^{N}$ the field work and data preparation, and Kate Bloor, who gave assistance at many points. The project was funded by the British Lung Foundation.

\section{References}

1 Department of Health and Social Security, Office of Population Censuses and Surveys, Welsh Office. Hosp- $\overrightarrow{\mathbb{D}}$

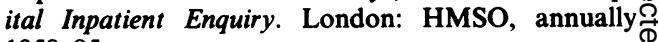
1958-85.

2 Mitchell EA. International trends in hospital admission 

rates for asthma. Arch Dis Child 1985;60:376-8.

3 Anderson HR. Increase in hospitalisation for childhood asthma. Arch Dis Child 1978;53:295-300.

4 Khot A, Burn R, Evans N, Lenney C, Lenney W. Seasonal variation and time trends in childhood asthma in England and Wales 1975-81. Br Med J 1984;289:235-7.

5 Anderson HR, Bailey P, West S. Trends in the hospital care of acute childhood asthma 1970-8: a regional study. Br Med J 1980;281:1191-4.

6 Office of Population Censuses and Surveys, Welsh Office. Mortality statistics. London: HMSO, annually 1958-85.

7 Anderson HR. The Epidemiological value of hospital diagnostic data. In: Bennett $\mathrm{AE}$, ed. Recent advances in community medicine 1. London: Churchill Livingstone,
1978:175-93.

8 Anderson HR. Is the prevalence of asthma changing? Arch Dis Child 1989;64:172-5.

9 Rees HA, Millar JS, Donald KW. A study of the clinical course and arterial blood gas tensions of patients in status asthmaticus. $Q J$ Med NS 1968;37:541-60.

10 Osman J, Ormerod P, Stableforth D. Management of acute asthma: a survey of hospital practice and comparison between thoracic and general physicians in Birmingham and Manchester. $\mathrm{Br} J$ Dis Chest 1987;81:232-41.

11 Simpson H, Forfar JO, Grubb DJ. Arterial blood gas tensions and $\mathrm{pH}$ in acute asthma in childhood. $\mathrm{Br} \mathrm{Med}$ $J$ 1968;iii:460-4.

12 Storr J, Barrell E, Lenney W. Rising asthma admissions and self referral. Arch Dis Child 1988;63:778-9. 